\title{
Social class, ethnic group, and male mortality in New Zealand, 1974-8
}

\author{
N E PEARCE,${ }^{1}$ P B DAVIS, ${ }^{2}$ A H SMITH, ${ }^{13}$ AND F H FOSTER \\ From the Department of Community Health, ${ }^{1}$ Wellington Clinical School, Wellington, New Zealand, the \\ Department of Community Health, ${ }^{2}$ Auckland Medical School, Auckland, New Zealand, the Department of \\ Biomedical and Environmental Health Sciences, ${ }^{3}$ School of Public Health, University of California, Berkeley, \\ CA 94720, United States, and the National Health Statistics Centre, ${ }^{4}$ Wellington, New Zealand
}

SUMMARY Social class mortality differences in New Zealand males aged 15 to 64 were investigated for the period 1974-8 using the Registrar-General's classification. The mortality gradient was similar to that previously found in England and Wales, but the New Zealand pattern was non-linear with particularly high mortality in class V. Smoking patterns accounted for much of the increased risk for classes III and IV but did not appear to explain the high mortality in class V. The patterns for the major disease groupings also paralleled those previously found in England and Wales, coronary heart disease and neoplasms displaying weaker gradients than accidents, respiratory diseases, digestive diseases, and infectious diseases. Maori and non-Maori males had comparable social class mortality gradients, but the Maori mortality rates were approximately $50 \%$ higher than the non-Maori rates in each class.

There has been extensive research in westernised countries showing relatively large social class differences in mortality. ${ }^{1-9}$ In particular, much of the evidence has come from the work of the British Registrar-General's Office on mortality in England and Wales during the past century. ${ }^{10-13}$ There has, however, been little research into social class mortality differences in New Zealand, and it has been asserted that "there is a tendency among many New Zealanders to deny the importance (and often the existence) of social strata". ${ }^{14}$

This paper arises from a series of studies investigating social class differences in male mortality in New Zealand. ${ }^{15-17}$ The Registrar-General's classification has been used throughout 1819 to provide comparability of the New Zealand patterns with those found in England and Wales. ${ }^{10-13}$ Social class differences in smoking have also been examined and their contribution to the New Zealand mortality differences assessed.

\section{Methods}

The denominator data were produced from a $10 \%$ sample of the 1976 New Zealand Census and the numerator data were obtained from the National Health Statistics Centre using computer tapes containing the records of all deaths registered in New Zealand during 1974-8. In each instance, persons were classified into social classes on the basis of the four-digit codes of the New Zealand Standard Classification of Occupations, ${ }^{20}$ which is a New Zealand adaptation of the International Standard Classification of Occupations. ${ }^{21}$

There were two principal reasons for restricting the study to the 15-64 age range: firstly, in order to make a comparison with the published British data; secondly, the occupational data for the older age group contained a relatively high proportion of retired people and invalids who could not be assigned to a social class on the basis of the occupational information on their death certificates. This was less of a problem in the 15-64 age range, however, and it was possible to classify $86 \%$ of the census data and $92 \%$ of the 24117 deaths into social classes. It was assumed that the unclassifiable data had the same age and class distribution as the classifiable data.

The cause of death was determined from the three-digit disease codes of the 8th revision of the International Classification of Diseases (ICD-8), and the data were grouped into the major disease categories used in the ICD-8 manual ${ }^{22}$ and in the Registrar-General's studies ${ }^{12}$-except that the 9 
split into three categories: coronary heart disease, cerebrovascular disease, and other diseases of the circulatory system.

The Maoris are the indigenous people of New Zealand whose ancestors migrated from East Polynesia and in 1976 constituted $9 \%$ of the male population aged 15-64. In New Zealand official statistics, a Maori is defined as a person having $50 \%$ or more Maori ancestry. The non-Maori category combines all other racial and ethnic divisions but is 95\% European; the other $5 \%$ is largely comprised of non-Maori polynesians. There are considerable classification problems however. ${ }^{23-25}$ In particular, there may be differences in information regarding ethnicity between the census and the death registration as the former is completed by the individual concerned whereas the latter is supplied by relatives and completed by the funeral director.

Directly age standardised mortality rates per 100000 person-years at risk were calculated for each social class and ethnic group using a computer program described in a previous paper. ${ }^{28}$ Five-year age groups were used throughout except for the comparisons of Maori and non-Maori rates where, because of the small denominators in Maori age strata in the higher social classes, it was necessary to use 10-year age strata and pool the data for the two highest social classes. In order to assess the effects of using 10-year rather than five-year age strata, the non-Maori data were analysed using both 10-year and five-year strata, and the difference in the results obtained was found to be negligible. Segi's world population was used as the standard, ${ }^{27}{ }^{28}$ and tests for trend with social class were performed using the Mantel-Haenszel extension test. ${ }^{29}$ The use of directly standardised rates, and the treatment of the unclassifiable data, differs from current practice for the Registrar-General's studies, ${ }^{12}$ but the social class mortality patterns for England and Wales 1970-2 did not change when the published data were reanalysed using the methods employed here. ${ }^{15}$

The smoking data were also produced from a $10 \%$ sample of the $1976 \mathrm{New}$ Zealand Census which asked individuals to classify themselves as current smokers, ex-smokers or non-smokers. It was possible to classify $97 \%$ of the responses into these three categories.

\section{Results}

Table 1 shows the social class distribution of employed males aged 15-64 for England and Wales 1971 and for New Zealand 1976. The distributions were very similar although the percentage of non-manual workers was higher in New Zealand $(41 \cdot 7 \%)$ than in England and Wales (35.6\%). Table 1 also shows the New Zealand social class distribution separately for Maoris and non-Maoris. Maoris were predominantly in occupations belonging to the lower social classes. Only $10 \cdot 8 \%$ of Maoris were in non-manual occupations compared with $42 \cdot 3 \%$ of non-Maoris.

Table 1 Social class distribution of employed males aged 15-64 for England and Wales 1971 and New Zealand 1976

\begin{tabular}{lcccc}
\hline & & & \multicolumn{2}{l}{ New Zealand } \\
\cline { 4 - 5 } $\begin{array}{l}\text { Registrar-General } \\
\text { Social Class }\end{array}$ & $\begin{array}{l}\text { England \& } \\
\text { Wales }\end{array}$ & $\begin{array}{l}\text { New } \\
\text { Zealand }\end{array}$ & Maori & Non-Maori \\
\hline I & 5.3 & 5.3 & 0.8 & 5.4 \\
II & 18.3 & 24.6 & 6.5 & 24.8 \\
IIIN & 12.0 & 11.8 & 3.5 & 12.1 \\
IIIM & 39.4 & 37.4 & 50.4 & 37.0 \\
IV & 17.4 & 15.3 & 23.0 & 15.2 \\
V & 7.7 & 5.8 & 15.8 & 5.4 \\
Total & $100.0 \%$ & $100.0 \%$ & $100.0 \%$ & $100.0 \%$ \\
\hline
\end{tabular}

Source: Pearce et al. ${ }^{15} 17$

TOTAL MORTALITY

Figure 1 shows the class specific mortality rates foㅁ. males aged 15-64 in New Zealand 1974-8. The overall mortality rate was 502 per $10000 œ$ 의 person-years at risk. A test for trend confirmed tha mortality was higher in the lower social classed $(p<0.001)$. The New Zealand gradient was significantly non-linear $(p<0.001)$, however, with 2 relatively high mortality rate for social class $\mathrm{V}$ and higher rate for class I than for class II.

MORTALITY BY MAJOR DISEASE GROUPINGS Table 2 shows the age-standardised mortality rates for each class and for each major disease grouping.

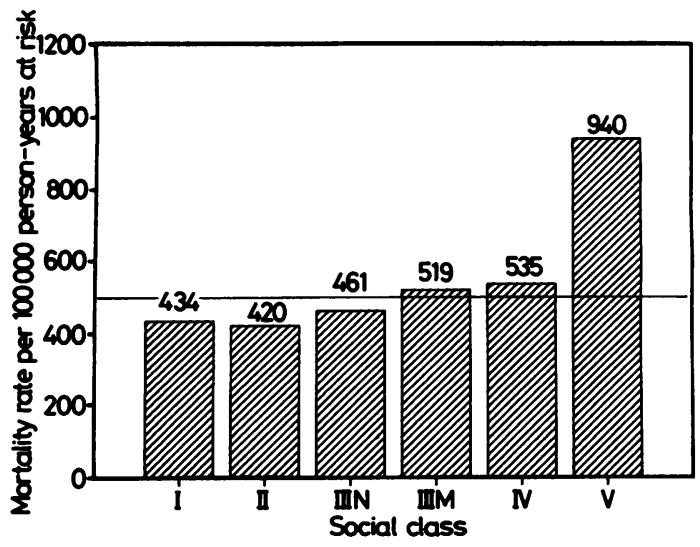

Fig 1 Age-standardised male mortality age 15-64, New Zealand 1974-8. By Registrar-General's social class. 
Table 2 New Zealand 1974-8 male age-standardised mortality per 100000 person-years at risk. By Registrar-General social class

\begin{tabular}{|c|c|c|c|c|c|c|c|c|c|}
\hline \multirow[b]{2}{*}{ Disease grouping } & \multirow[b]{2}{*}{ ICD Nos. } & \multicolumn{6}{|l|}{ Class } & \multicolumn{2}{|l|}{ p-value } \\
\hline & & $I$ & II & IIIN & IIIM & IV & $\boldsymbol{V}$ & For trend & For linearity \\
\hline Coronary heart & $410-414$ & 171.9 & $147 \cdot 3$ & 173.9 & $162 \cdot 7$ & $158 \cdot 2$ & $238 \cdot 0$ & $<0.001$ & $<0.001$ \\
\hline Neoplasms & $140-239$ & $96 \cdot 2$ & $101 \cdot 0$ & $112 \cdot 1$ & $122 \cdot 2$ & $106 \cdot 2$ & $167 \cdot 7$ & $<0.001$ & 0.065 \\
\hline Accidents, etc & $800-999$ & $67 \cdot 6$ & $76 \cdot 7$ & $65 \cdot 1$ & $95 \cdot 1$ & 123.6 & $202 \cdot 6$ & $<0.001$ & $<0.001$ \\
\hline Circulatory & $390-459^{*}$ & $20 \cdot 5$ & $20 \cdot 5$ & $19 \cdot 4$ & $29 \cdot 6$ & $29 \cdot 9$ & $73 \cdot 3$ & $<0.001$ & $<0.001$ \\
\hline Respiratory & $460-519$ & 14.9 & $16 \cdot 3$ & $21 \cdot 1$ & $31 \cdot 7$ & $20 \cdot 0$ & 73.0 & $<0.001$ & $<0.001$ \\
\hline Cerebrovascular & $430-438$ & $26 \cdot 7$ & 20.4 & 23.6 & 29.8 & $28 \cdot 3$ & $51 \cdot 1$ & $<0.001$ & 0.027 \\
\hline Digestive & $520-579$ & 8.9 & $10 \cdot 7$ & $15 \cdot 1$ & $15 \cdot 2$ & $17 \cdot 1$ & $44 \cdot 0$ & $<0.001$ & $<0.001$ \\
\hline Endocrine & $240-279$ & $9 \cdot 8$ & $9 \cdot 2$ & $7 \cdot 4$ & $10 \cdot 1$ & $10 \cdot 2$ & $21 \cdot 6$ & $<0.001$ & $<0.001$ \\
\hline Nervous system & $320-389$ & $5 \cdot 1$ & $4 \cdot 5$ & $7 \cdot 6$ & 5.4 & 7.6 & $15 \cdot 9$ & $<0.001$ & $<0.001$ \\
\hline Mental & $290-319$ & $3 \cdot 6$ & $2 \cdot 7$ & 3.9 & $5 \cdot 5$ & $8 \cdot 0$ & $18 \cdot 9$ & $<0.001$ & $<0.001$ \\
\hline Infectious & $0-139$ & $3 \cdot 5$ & $2 \cdot 6$ & $2 \cdot 2$ & $4 \cdot 2$ & $5 \cdot 5$ & $16 \cdot 0$ & $<0.001$ & 0.023 \\
\hline Genitourinary & $580-629$ & $1 \cdot 8$ & 3.0 & 2.6 & 3.9 & $4 \cdot 2$ & $6 \cdot 8$ & $<0.001$ & 0.113 \\
\hline Congenital & $740-759$ & $2 \cdot 1$ & $1 \cdot 8$ & 3.0 & 1.6 & $3 \cdot 2$ & 4.9 & 0.092 & 0.003 \\
\hline Other & & $2 \cdot 2$ & $3 \cdot 3$ & $3 \cdot 4$ & $2 \cdot 5$ & 2.9 & $6 \cdot 5$ & 0.516 & 0.019 \\
\hline Total mortality & 0-999 & $434 \cdot 7$ & 420.0 & $460 \cdot 5$ & $519 \cdot 4$ & $535 \cdot 0$ & $940 \cdot 3$ & $<0.001$ & $<0.001$ \\
\hline
\end{tabular}

-Excluding 410-414 and 430-438.

Except for congenital anomalies and the "other" grouping there was a highly significant gradient for each disease grouping, but the pattern was once again non-linear in many cases, the lowest mortality rates being for classes II or IIIN rather than for class I.

\section{MORTALITY BY ETHNIC GROUP}

The social class mortality patterns for Maoris and non-Maoris are shown in figure 2. Both groups experienced statistically significant social class mortality gradients $(p<0.001)$, but for each social class the Maori mortality rates were greater than the non-Maori rates.

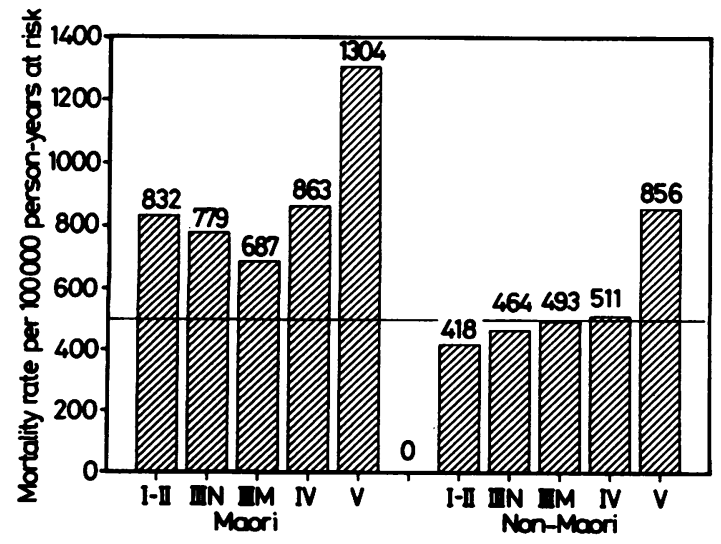

Fig 2 Age-standardised male mortality age 15-64, New Zealand 1974-8. By Registrar-General's social class and ethnic group.
Table 3 quantifies the extent to which these social class mortality gradients account for the different mortality patterns in Maoris and non-Maoris. The first column gives the observed number of deaths while the second gives the age-standardised mortality ratio (SMR) which calculates the observed deaths as a percentage of the number of deaths expected on the basis of the non-Maori mortality rates in each age group. The third column gives the SMR standardised for social class as well as for age. Overall there were $\mathbf{7 4 \%}$ more Maori deaths than there would have been if Maoris had experienced the same mortality rates as non-Maoris in each age group, and 53\% more than there would have been if Maoris had experienced the same mortality rates as non-Maoris in each class and each age group.

Table 3 Mortality 1974-8 among Maori males aged 15-64 standardised for age and Registrar-General social class.

\begin{tabular}{lrrrrr}
\hline & & & \multicolumn{2}{l}{$S M R$ adjusted } & $\begin{array}{l}\text { \% of excess } \\
\text { attributable }\end{array}$ \\
\cline { 5 - 6 } Disease grouping & ICD Nos & $\begin{array}{l}\text { Observed } \\
\text { deaths }\end{array}$ & For age & For age/class & to social class \\
\hline Coronary heart & $410-414$ & 411 & 124 & 119 & 18 \\
Neoplasms & $140-239$ & 326 & 132 & 123 & 22 \\
Accidents, etc & $800-999$ & 528 & 146 & 127 & 34 \\
Circulatory & $390-459^{*}$ & 221 & 404 & 320 & 9 \\
Respiratory & $460-519$ & 187 & 348 & 254 & 15 \\
Cerebrovascular & $430-438$ & 79 & 141 & 119 & 45 \\
Digestive & $520-579$ & 73 & 230 & 171 & 27 \\
Endocrine & $240-279$ & 108 & 578 & 502 & 3 \\
Nervous system & $320-389$ & 33 & 180 & 140 & 36 \\
Mental & $290-319$ & 25 & 180 & 122 & 59 \\
Infectious & $0-139$ & 61 & 763 & 565 & 5 \\
Genitourinary & $580-629$ & 40 & 548 & 471 & 4 \\
Congenital & $740-759$ & 13 & 165 & 140 & 27 \\
Other & & 14 & 203 & 177 & 14 \\
& & & & & 18 \\
Total mortality & $0-999$ & 2119 & 174 & 153 & \\
\hline
\end{tabular}

"Excluding 410-414 and 430-438. 
The fourth column calculated the percentage of the excess deaths that were attributable to social class. Overall, when the data were adjusted for age, there were 903 more Maori deaths than expected on the basis of the non-Maori rates $(S M R=174)$ and there were 738 excess deaths still remaining when the data were adjusted for age and social class $(\mathrm{SMR}=153)$. Hence $18 \%$ (165) of the excess Maori deaths were attributable to social class factors and $82 \%$ were not.

The pattern was not the same for all disease groupings however. The SMRs for coronary heart disease, neoplasms, accidents, poisonings and violence, and cerebrovascular disease were not excessively high, and these were reduced still further when the data were adjusted for social class. On the other hand, there were a number of disease groupings including other circulatory diseases, respiratory diseases, endocrine diseases, infectious diseases, and genitourinary diseases which had relatively high SMRs which were reduced only slightly when the data were adjusted for social class.

\section{SMOKING}

There are two main features to fig 3 which shows the age-standardised percentage of smokers for each social class. Firstly, there was a clear social class gradient for the percentage of current smokers. Secondly, the gradient for current smokers and ex-smokers combined was less marked as there was a relatively high percentage of ex-smokers among the upper social classess. In fact $50 \%$ of class I males who had ever smoked classified themselves as ex-smokers compared with $25 \%$ of class $\mathrm{V}$ males.

Appropriate data were not available to assess the contribution of smoking to the social class mortality

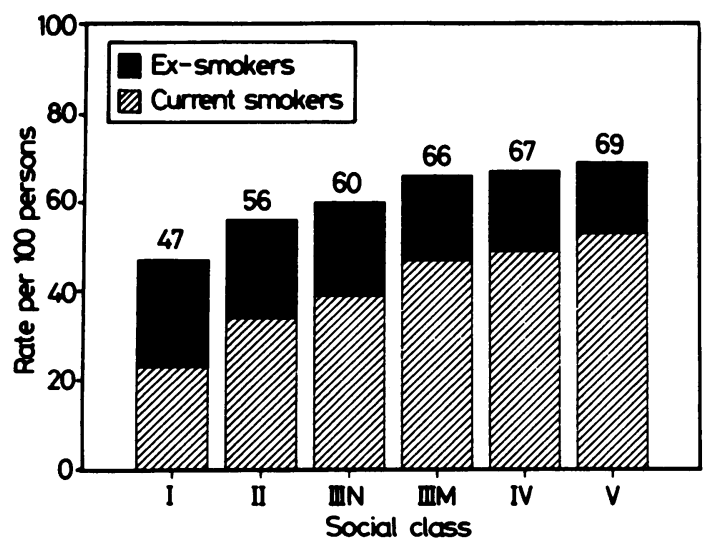

Fig 3 Age-standardised 1976 New Zealand male smoking rates age 15-64. By Registrar-General's social class. differences, but an estimation of the order of magnitude can be obtained from the calculations presented in table 4 . These assume an approximate relative risk for all causes mortality of 2.0 for smokers and 1.5 for ex-smokers compared to non-smokers. These very approximate figures were derived from the British doctors study data for males aged $30-64 .{ }^{30}$ Table 4 uses these estimates to calculate the expected relative risk-on the basis of the smoking data-for each class compared to classes I-II. These crude calculations suggest that the smoking patterns explain much of the increased risk for classes III-IV but not the very high mortality for class $\mathrm{V}$.

Table 4 Expected relative risks for classes IIIN- $V$ v classes I-II based on age-standardised smoking rates from 1976 Census

\begin{tabular}{lllllll}
\hline $\begin{array}{l}\text { Registrar- } \\
\begin{array}{l}\text { General } \\
\text { social class smokers }\end{array}\end{array}$ & $\begin{array}{l}\text { Non- } \\
\text { Ex- }\end{array}$ & $\begin{array}{l}\% \\
\text { smokers }\end{array}$ & $\begin{array}{l}\text { Current } \\
\text { smokers }\end{array}$ & \multicolumn{2}{l}{ Relative risk v classes I-II } \\
\cline { 6 - 8 } & & & Expected & Observed \\
\hline I-II & 46.0 & 21.9 & 32.1 & - & - & \\
IIIN & 40.1 & 20.9 & 39.0 & 1.045 & 1.090 & \\
IIM & 33.9 & 19.3 & 46.7 & 1.092 & 1.229 & \\
IV & 32.7 & 18.6 & 48.7 & 1.104 & 1.266 & \\
V & 31.0 & 16.0 & 53.0 & 1.125 & 2.225 & \\
\hline
\end{tabular}

\section{Discussion}

An important finding of this study was that New Zealand mortality patterns were similar to those found in England and Wales for overall mortality and for each major disease grouping. The New Zealand pattern was significantly non-linear, however, suggesting that the British scale may not be completely applicable to New Zealand, or that there may be some real differences in mortality patterns by social class. In fact the former appears to be the case since a linear gradient, of similar strength, was found when a New Zealand scale based on an equal weighting of education and income was used. ${ }^{15}$

As in England and Wales, the major disease groupings can be into two main categories corresponding to the distinction that Blaxter and others draw between the traditional diseases of $₹$ poverty and the modern diseases of affluence. ${ }^{31}{ }^{32} \mathrm{O}$ The former category includes the disease groupings $D$ that were dominant in the 19 th and early 20th centuries and which exhibited strong social class gradients - such as respiratory disease, infectious or disease, and accidents. The latter category includes $\mathcal{N}$ disease groupings such as coronary heart disease and $\underset{\omega}{N}$ neoplasms, which show relatively weak social class 우 gradients in the New Zealand and British data. The 0 
former disease groupings have retained their social class gradients in England and Wales for the past century whereas the modern diseases of affluence had gradients in the opposite direction earlier this century but have now reversed their social class gradients and exhibit similar-though less extreme-patterns to those of the more traditional disease groupings. ${ }^{31-34}$ It is apparent that the so-called diseases of poverty do conform in New Zealand to the British pattern and exhibit strong social class mortality gradients. It is also apparent that in New Zealand the modern diseases of affluence are now paralleling the post-war British pattern. However, without further research we are unable to ascertain whether New Zealand also follows the British pattern in having reversed gradients for these diseases at an earlier period of its history.

Apart from the problems of non-linearity, the British and New Zealand patterns are strikingly similar for overall mortality and for each major disease grouping. Tables 2 and 4 have shown that accidents and smoking make contributions to the social class mortality gradients in New Zealand similar to those in England and Wales but they acccounted for only about one half of the excess mortality in classes III-IV and much less than that in class $\mathrm{V}$. On the other hand, it is difficult to suggest what other common factors might be contributing to the similarity in social class mortality gradients. In fact, although a large proportion of New Zealanders are migrants, or descendants of migrants, from the United Kingdom ${ }^{35}$ there are some distinct social and environmental differences. These include differences in climate with a more temperate climate in New Zealand, ${ }^{35}$ a much lower population density, ${ }^{35}$ comparatively greater social mobility, ${ }^{36}$ an economy based on agriculture and processing of agricultural products with high consumption of relatively cheap, locally produced food items, ${ }^{37}{ }^{38}$ and a country with greater participation in sport and more opportunity for outdoor activities. ${ }^{39}$ In spite of these differences, similar social class mortality gradients were found, not only for overall mortality but also for mortality from the major disease groupings examined.

Another important finding from the New Zealand data was that Maori and non-Maori males experienced similar social class mortality gradients, but Maori mortality rates were approximately $50 \%$ higher than the non-Maori rates in each social class. The interaction of ethnicity and social class is particularly interesting as there were some disease groupings such as coronary heart disease, neoplasms, accidents, poisonings and violence, cerebrovascular disease, and mental disorders for which the Maori mortality was not excessively high-particularly when social class factors were taken into account.
Other disease groupings had relatively high Maori mortality even when social class factors were taken into account. Overall there were substantial social class differences and ethnic differences in mortality, and these were largely independent so that four-fifths of the Maori mortality excess was not attributable to social class-at least as measured by occupation. This non-social class related excess has been examined in a further paper which found that $15 \%$ of it was linked with cigarette smoking, $10 \%$ with alcohol consumption, $5 \%$ with obesity, and $17 \%$ with accidents. ${ }^{40}$

However, $36 \%$ of the non-social class related excess involved rheumatic and hypertensive heart disease, nephritis, bronchiectasis, diabetes, and tuberculosis, which were all associated with a Maori mortality five or more times that for non Maoris. ${ }^{40}$ Further studies of these diseases are needed to identify the causes of these marked differences.

Salary support for Neil Pearce is from a grant from the Medical Research Council of New Zealand to the Wellington Clinical School. The work by Peter Davis on social class measurement and classification was supported by grants from the Medical Research Council of New Zealand and from the Auckland Division of the New Zealand Cancer Society. We thank Gillian Knowles of the Statistics Department for advice on systems of social class classification, and Mr M A Moore of the Statistics Department for assistance with the Cents-Aid II package and for analysing the 1976 New Zealand Census data. We also thank $\operatorname{Dr} R$ Beaglehole, $\operatorname{Dr} J$ G Joseph, Professor K W Newell, Dr P Ngata, Dr E W Pomare, Professor D I Pool, Dr I A M Prior, and Dr M Taikato for advice and encouragement.

Requests for reprints to: Neil Pearce, Department of Community Health, Wellington Clinical School, Wellington Hospital, Wellington, New Zealand.

\section{References}

${ }^{1}$ Antonovsky A. Social class, life expectancy and overall mortality. Milbank Mem Fund $Q$ 1967; 45: 31-73.

${ }^{2}$ Yeracaris CA. Differential mortality, general and cause-specific in Buffalo, 1939-41.J Am Statist Assoc 1955; 50: $1235-47$.

${ }^{3}$ Graham S. Socio-economic status, illness, and the use of medical services. Milbank Mem Fund $Q$ 1957; 35: 58-66.

4 Stockwell EG. Socioeconomic status and mortality in the United States. Public Health Rep 1961; 76: 1081-6.

${ }^{5}$ Stockwell EG. A critical examination of the relationship between socioeconomic status and mortality. Am J Public Health 1963; 53: 956-64. 
${ }^{6}$ Nagi MH, Stockwell EG. Socioeconomic differentials in mortality by cause of death. Public Health Rep 1973; 88: 449-65.

${ }^{7}$ Kitagawa EM, Hauser PM. Differential mortality in the United States. Cambridge: Harvard University Press, 1973.

${ }^{8}$ Nayha S. Social group and mortality in Finland. Br J Prev Soc Med 1977; 31: 231-7.

${ }^{9}$ Holme I, Helgeland A, Hjermann I et al. Four year mortality by some socioeconomic indicators: the Oslo study.J Epidemiol Community Health 1980; 34: 48-52.

${ }^{10}$ Office of Population Censuses and Surveys. Occupational mortality, 1950-1953. Decennial supplement. London: HMSO, 1957.

${ }^{11}$ Office of Population Censuses and Surveys. Occupational mortality, 1959-1963. Decennial supplement. London: HMSO, 1971.

${ }^{12}$ Official of Population Censuses and Surveys. Occupational mortality, 1970-1972. Decennial supplement. London: HMSO, 1978.

${ }^{13}$ Fox J. Occupational mortality 1970-72. Population Trends 1977; 7: 1-8.

${ }^{14}$ Collette J. Social stratification in New Zealand. In: Webb SD, Collette J (eds). New Zeland society: Contemporary perspectives. Sydney: John Wiley, 1973.

${ }^{15}$ Pearce NE, Davis PB, Smith AH, et al. Mortality and social class in New Zealand. I: Overall male mortality. NZ Med J 1983; 96: 281-5.

${ }^{16}$ Pearce NE, Davis PB, Smith AH, et al. Mortality and social class in New Zealand. II: Male mortality by major disease groupings. $N Z$ Med J 1983; 96: 711-6.

${ }^{17}$ Pearce NE, Davis PB, Smith AH, et al. Mortality and social class in New Zealand. III: Male mortality by ethnic group. $N Z$ Med J 1984; 97: 31-5.

${ }^{18}$ Leete R, Fox J. Registrar General's social classes: origins and uses. Population Trends 1977; 8: 1-7.

${ }^{19}$ Office of Population Censuses and Surveys. Classification of occupations. London: HMSO, 1980.

${ }^{20}$ Department of Statistics. New Zealand standard classification of occupations. Wellington: Department of Statistics, 1980.

${ }^{21}$ International Labour Office. International standard classification of occupations. Geneva: ILO, 1968.

${ }^{22}$ World Health Organisation. Manual of the international statistical classification of diseases, injuries and causes of death. 8th revision. Geneva: WHO, 1967.

${ }^{23}$ Pool DI. When is a Maori a "Maori"? J Polynesian Soc 1963; 72: 206-10.
${ }^{24}$ Pool DI. The Maori population of New Zealand 1769-1971. Auckland: Auckland University Press, 1977.

${ }^{25}$ Pool DI. New Zealand: ethnic questions in the census and other official data. New Community 1981; 9: 91-7.

${ }^{26}$ Pearce NE, Smith AH. A generalised computer program for analysis of New Zealand mortality (and incidence) rates. Community Health Studies 1980; 3: 260.

${ }^{27}$ Waterhouse J, Muir C, Correa $\mathrm{P}$, et al (eds). Cancer incidence in five continents. Vol 3. Lyon: IARC, 1976.

${ }^{28}$ Segi M. Cancer mortality for selected sites in 24 countries (1950-1957). Sendai, Japan: Department of Public Health, Tohoku University School of Medicine, 1960.

${ }^{29}$ Mantel N. Chi-square tests with one degree of freedom: Extensions of the Mantel-Haenszel procedure. J Am Statist Assoc 1963; 58: 690-700.

${ }^{30}$ Doll R, Peto R. Mortality in relation to smoking: 20 years' observations on male British doctors. $\mathrm{Br} \mathrm{Med} J$ 1976; 2: 1525-36.

${ }^{31}$ Blaxter M. Social class and health inequalities. In: Couter $\mathrm{C}$, Peel $\mathrm{J}$ (eds). Equalities and inequalities in health. London: Academic Press, 1976.

${ }^{32}$ Susser MW. Watson W. Sociology in medicine. London: Oxford University Press, 1971.

${ }^{33}$ Marmot MG, Adelstein AM, Robinson N, et al. Changing social class distribution of heart disease. $\mathrm{Br}$ Med J 1978; 2: 1109-12.

${ }^{34}$ Logan WPD. Cancer mortality by occupation and social class 1851-1971. London: HMSO, 1982.

${ }^{35}$ Department of Statistics. New Zealand Official Yearboo 1981. 86th annual edition. Wellington: Department Statistics, 1981.

${ }^{36}$ Davis PB. Social mobility in New Zealand: Preliminar results from a national survey. Aust NZ J Sociol 1979 15: 50-6.

${ }^{37}$ Birkbeck JA. New Zealanders and their diet. Aucklang National Heart Foundation, 1979.

${ }^{38}$ Birkbeck JA. The role of dairy products in the Ne Zealand diet. NZ Med J 1981; 84: 386-9.

${ }^{39}$ Beaglehole R, Hay DR, Foster FH, Sharpe DN. Trends in coronary heart disease and associated risk factors in New Zealand. $N Z$ Med $J$ 1981; 93: 371-5.

${ }^{40}$ Smith AH, Pearce NE. Determinants of differences in mortality between New Zealand Maoris and non-Maoris aged 15-64. NZ Med J 1984; 97: 101-8. 